\title{
Trajectories of neuropsychological functioning in Mexican children with traumatic brain injury over the first year after injury
}

\author{
D. Ramos-Usuga a ${ }^{\text {, I. Benito-Sánchez }}{ }^{\mathrm{a}, \mathrm{b}}$, P. Pérez-Delgadillo ${ }^{\mathrm{d}}$, R. Valdivia-Tangarife ${ }^{\mathrm{e}}$, \\ T. Villaseñor-Cabrera ${ }^{\mathrm{e}, \mathrm{f}}$, L. Olabarrieta-Landa ${ }^{\mathrm{g}}$ and J.C. Arango-Lasprilla $^{\mathrm{b}, \mathrm{c}, \mathrm{h}, *}$ \\ ${ }^{a}$ Biomedical Research Doctorate Program, University of the Basque Country (UPV/EHU), Leioa, Spain \\ ${ }^{\mathrm{b}}$ BioCruces Bizkaia Health Research Institute, Barakaldo, Spain \\ ${ }^{\mathrm{c}}$ Department of Cell Biology and Histology, University of the Basque Country (UPV/EHU), Leioa, Spain \\ ${ }^{\mathrm{d}}$ Rusk Rehabilitation at New York University Langone Health, New York, NY, USA \\ ${ }^{\mathrm{e}}$ Department of Psychology, University of Guadalajara, Guadalajara, Mexico \\ ${ }^{\mathrm{f}}$ Department of Neurosciences, University of Guadalajara, Guadalajara, Mexico

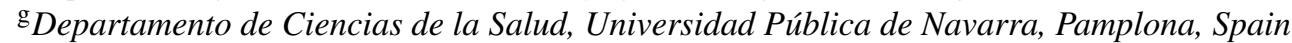 \\ h IKERBASQUE, Basque Foundation for Science, Bilbao, Spain
}

\begin{abstract}
.
BACKGROUND: Children with traumatic brain injury (TBI) usually displayed substantial neuropsychological impairment at short and long term after injury.

OBJECTIVE: To compare the course of cognitive functioning among children with TBI and healthy controls over the first-year post-injury in Guadalajara, Mexico.

METHODS: A sample of 46 children with TBI and 46 healthy controls from Guadalajara, Mexico were recruited. Both groups received a comprehensive neuropsychological evaluation at three-time (3, 6, and 12 months) with measures of memory, attention, executive function, processing speed, language, perceptual reasoning, visuo-spatial abilities, and intellectual functioning. Sixteen hierarchical linear models (HLMs) were performed to examine whether linear trajectories of cognitive functioning differed over time between groups.

RESULTS: Trajectories of neuropsychological performance were significantly worse over time among children with TBI than healthy controls across every cognitive domain. HLMs suggested that cognitive performance increased over time in both groups, however, TBI group scored significantly lower at each time point compare to the control group, except in Stroop-Interference.

CONCLUSIONS: Cognitive deficits are common during the first-year after pediatric TBI. Thus, it is imperative to implement early rehabilitation programs to mitigate the consequences of these problems in the social, academic, and family reintegration of these children.
\end{abstract}

Keywords: TBI, children, cognitive function, Mexico, Latin America

ORCHID no.: 0000-0002-7184-8311

*Address for correspondence: Dr. Juan Carlos ArangoLasprilla, BioCruces Bizkaia Health Research Institute, Cruces University Hospital, IKERBASQUE. Basque Foundation for
Science, Plaza de Cruces s/n. 48903, Barakaldo, Bizkaia, Spain. E-mail: jcalasprilla@gmail.com. 


\section{Introduction}

Traumatic Brain Injury (TBI) is considered to be the leading cause of death and disability in children and adolescents around the world (Fulton, Yeates, Taylor, Walz, \& Wade, 2012). The worldwide incidence of pediatric TBI ranges between 47 and 280 per 100,000 children depending of the country, and with the vast majority of them $(80 \%)$ being classified as mild TBI (Dewan, Mummareddy, Wellons III, \& Bonfield, 2016). Children who sustain severe head injuries tend to present with permanent or temporary impairment of cognitive (Allen et al., 2010; Hawley, Ward, Magnay, \& Long, 2004), behavioural (Butler, Rourke, Fuerst, \& Fisk, 1997; Hawley et al., 2004), academic (Ewing-Cobbs et al., 2004), psychosocial (Hawley et al., 2004; Maxwell, 2012), and physical functions, which may often interrupt efficient learning and adequate social reintegration (KuhtzBuschbeck et al., 2003).

Although many of these impairments in functioning may be resolved spontaneously (Da Dalt et al., 2006) or reduced in severity during the acute stages of recovery (Anderson, Godfrey, Rosenfeld, \& Catroppa, 2012a; Jonsson, Catroppa, Godfrey, Smedler, \& Anderson, 2013; Ryan et al., 2015), many children continue to experience negative outcomes despite evident recovery (Wade, Taylor, Drotar, Stancin, \& Yeates, 1996), especially in terms of academic achievement and subsequent placement in special education programs (Kinsella et al., 1997), with marked persistent deficits in those enduring severe TBI (Ewing-Cobbs et al., 2004) and challenges with social integration (Anderson et al., 2012a), adversely disrupting their quality of life and family relationships (Hawley, Ward, Magnay, \& Long, 2003), and resulting in greater social and economic costs (Daneshvar et al., 2011).

Among the deficits typically observed in children with TBI, cognitive problems appear to be more enduring over time, as brain plasticity may not occur in areas of severe pathology, and new cognitive impairments emerge as anticipated developmental milestones are not met (Anderson, Catroppa, Rosenfeld, Haritou, \& Morse, 2000). Several studies have explored the sequelae post TBI and identified cognitive impairments in the areas of attention (Allen et al., 2010; Anderson et al., 2012b; Dennis, Wilkinson, Koski, \& Humphreys, 1995), memory/learning (Allen et al., 2010; Anderson \& Catroppa, 2007; Crowther et al., 2011), language (Demir, Levine, \& Goldin-Meadow, 2010), executive functioning
(EF; Chevignard, Catroppa, Galvin, \& Anderson, 2010; Crowe, Catroppa, Babl, \& Anderson, 2013; Maillard-Wermelinger et al., 2009), processing speed (Kirkwood et al., 2008), and visuospatial construction skills (Thompson et al., 1994) that may persist for several months to a lifetime (Anderson, Catroppa, Morse, Haritou, \& Rosenfeld, 2001).

Today, the literature has shown that most research studies investigating the cognitive impact of TBI in children have been cross-sectional. Consequently, very few longitudinal studies aiming to explore the course of cognitive impairment following TBI over time exist to date. For instance, Ewing-Cobbs et al. (1997) studied the intellectual and language functioning of a group of 79 children from Texas, United States of America (USA), between the ages of 2 and 12 years, 11 months with mild, moderate, and severe TBI. Assessments were conducted at baseline, 6 months, 12 months, and 24 months, with outcomes denoting global deficits for infant and toddlers in the severe range, with particular insufficiencies in expressive and receptive language, and lower performance on motor functioning when compared to intelligence quotient (IQ). Moreover, TBI severity was identified as a predictor of language performance, with mild to moderate severity ranges yielding lower expressive language performance.

In 2006, Arroyos-Jurado, Paulsen, Ehly, \& Max (2006) also studied the cognitive, learning and memory functioning of a group of 27 children with TBI between the ages of 6 and 14 years from Midwest USA. Initial assessment was conducted at baseline, with follow-up evaluations at 3, 12, 24, and 72-96 months, as well as $6-8$ years post TBI. Outcomes indicated that the severity of injury had a significant impact on nonverbal IQ performance, while performance IQ worsened from baseline to 6-8 years later for severe TBI patients. Moreover, children and adolescents with more severe head injuries used less effective learning strategies to encode and recall information.

Nadebaum, Anderson, \& Catroppa (2007) explored the EF of 71 children with TBI in Australia, between the ages of 0 and 7 years and respective functional assessment at baseline and 5 years post injury. Results were indicative of executive difficulties following severe TBI, whereas the EF of children enduring mild to moderate injuries remained relatively unaffected. In 2008, Catroppa, Anderson, Morse, Haritou, \& Rosenfeld analyzed the intellectual, academic, and behavioral functioning of 48 children aged between 2 and 6 years, 11 
months following a TBI at 6 months, 30 months, and 5 years post injury. Outcomes indicated lower IQ performance for severe TBI participants, while greater injury severity was correlated to poorer academic performance in word decoding, spelling, and arithmetic.

Maillard-Wermelinger et al. (2009) studied the EF of a larger subject sample of 186 children from Ohio, USA, between 8 and 15 years of age at baseline, 3 and 6 months post mild TBI, and compared them to a mild orthopedic injury (OI) group. Surprisingly, while no group performance differences were observed in a spatial planning task, mild TBI participants performed better than the mild OI group participants on spatial working memory. Regarding behavioral manifestations of EF, the TBI group evidenced a marginal significance towards more problems than the OI group on the Metacognition Index composite, with significantly more problems on the Organization of Materials. Similarly, Fay et al. (2009) explored the intellectual, cognitive, and academic functioning of 77 children between the ages of 6 and 12 years at 6 and 12 months, as well as 3-5 years post mild and severe TBI in Ohio, USA. Results were indicative of severe TBI being associated with lower functioning across all domains evaluated (neuropsychological, academic, behavioral, and adaptive). Interestingly, outcome results also denoted that many children with severe TBI showed no deficits between 6 months to 4 years' post injury in one or more outcome domains.

Anderson et al. (2012a) studied the intellectual, adaptive, and behavioral functioning of a group of 76 children between 2 and 12 years of age from Melbourne, Australia, 10 years post TBI injury. Findings indicated statistically significant differences on adaptive ability and processing speed, with more severe injury consistently correlated with poorer outcomes. A similar trend with a small-medium effect size was observed on intellectual and executive functioning outcomes for the severe TBI group. Moreover, severe and moderate TBI recorded a greater drop in adaptive abilities. Crowther et al. (2011) targeted the learning, memory, and metamemory of 167 children from Texas, USA, between the ages of 5 and 15 . Analysis included functional assessment at baseline, $3,6,12$, and 24 months post injury, with outcome results indicating that greater TBI severity was related to poorer performance on prospective metamemory judgements, but not retrospective judgements. Additionally, while TBI severity did not affect initial study recall performance, groups did vary in performance with repeated study.
In 2012, Pomerleau et al. (2012) evaluated the language functioning and adaptive behavior of a group of 31 children from Montreal, Canada, at baseline, 9, 18, 30, and 42 months post TBI injury. Results indicated that $15-20 \%$ of the children presented with clinically significant motor and/or language delays while by 42 months, difficulties with adaptive behaviors, and personal social abilities were noticed. Moreover, qualitative findings identified between $25-50 \%$ of children with potential attentional difficulties during the follow up period. Also, in 2012, Anderson et al. (2012c) explored the intellectual functioning of 76 children in Australia by dividing in two groups of 2 to 7 years, and $8-12$ years, respectively. Outcome results identified elevated levels of impairment with severe TBI (global deficits) and early injury (non-verbal deficits). Impairments in processing speed were associated to injury severity and younger age at injury. However, between 30 months and 10 years post injury, children appeared to make adequate developmental gains.

Jonsson et al. (2013) assessed the verbal comprehension, perceptual organization, freedom from distractibility, and processing speed of a group of 118 children in Australia, between the ages of 3 and 12 years, 11 months at 30 months and 10 years post injury. Slower development was identified in children with below average functioning, and especially low verbal comprehension. Likewise, Ryan et al. (2015) evaluated pragmatic language skills in a group of 112 children in Australia between the ages of 5 and 15 at 6- and 24-months post TBI. Results were indicative of impairments in all domains for both children and adolescents with TBI of all severity levels at 6months post injury before returning to age-expected levels at 2-years post TBI. However, while adolescent TBI was associated with post-acute disruption to skills that preceded recovery to age-expected levels by 2 -years post TBI, the middle childhood TBI group exhibited deficiencies at 6-months post injury that were sustained at 2-year follow up.

Van Beek, Vanderauwera, Ghesquière, Lagae, \& De Smedt (2015) evaluated the mathematical abilities and working memory of a group of 20 children between 7 and 13 years of age at baseline, 6 , and 8 months post injury, identifying working memory deficits that persevered in the follow ups.

More recently, Gorman, Barnes, Swank, \& EwingCobbs (2017) evaluated the intellectual functioning, verbal working memory and visuospatial span in a group of 55 children from Texas, USA at 2, 6, 12, and 24 months post injury. These authors found that 
the youngest children with severe TBI had the lowest scores and lowest verbal working memory growth, and that working memory outcome is best mediated by age at injury and TBI severity. Treble-Barna et al. (2017) studied the verbal learning, fluid reasoning, $\mathrm{EF}$, attention, processing speed, and adaptive functioning of a group of 58 children between 3 and 7 years from Ohio, USA. Functioning assessments were conducted at 6,12 , and 18 months, as well as 3.5- and 6.9-years post injury and compared to a group of OI children, where children with severe TBI demonstrated poorer fluid reasoning and inhibitory control than both children with moderate TBI and OI, as well as slower processing speed than the OI group.

Krasny-Pacini et al. (2017) analyzed the EF post severe TBI of 65 children between the ages of 0 and 15 years in France, at 3, 6, 12, and 24 months. Results were indicative of significant impairment in working memory, inhibition, attention, and global EF in children with severe TBI. Moreover, performancebased EF scores evidenced significant improvement at 12 and 24 months when compared to 3 months post injury. In Canada, Bellerose, Bernier, Beaudoin, Gravel, \& Beauchamp (2017) followed a group of 72 children between 1.5 and 5 years of age at 6 and 18 months post mild TBI and evaluated their theory of mind abilities. Findings indicated that statistically significant differences were observed on adaptive ability and processing speed scores, with more severe injury consistently correlated with poorer outcomes. A similar trend with a small-medium effect size was observed on intellectual and EF outcomes for the severe TBI group. However, contrary to other studies reported in this article regarding mild injuries, the group differences (mild TBI and OI) on these tasks were sustained 18 months post injury.

As observed in the previously discussed literature, the vast majority of longitudinal studies exploring post TBI cognitive deficits in children have included all TBI severities (mild, moderate, and severe), and have been conducted with samples primarily composed of school aged children, between the ages of 5 and 10, and completed mainly in English speaking countries such as USA, Canada, and Australia. The times post TBI at which most of the evaluations were conducted was observed to range between 3 to 24 months, with a few of the studies extending between 5 to 10 years. EF was the cognitive domain most frequently assessed, followed by memory, learning, and language functioning. Working memory (except for visuo-spatial), inhibition, attention, and language deficits were the most commonly reported findings across research studies, often mediated by age and injury severity, with severe TBI leading to greater deficits in fluid reasoning and processing speed before returning to age expected levels at 24 months, typically.

Given the practice of neuropsychology and available resources in the countries where these research studies have been conducted, cognitive rehabilitation may have been part of the rehabilitation treatment received, although frequency and intensity of such services has not been clearly identified in the literature. To this date, longitudinal studies exploring the long lasting cognitive, behavioral, and emotional impact of mild, moderate, or severe TBI in the pediatric Latin American population are non-existent, despite TBI being highly prevalent in Latin American children (Puvanachandra \& Hyder, 2008), many who may have limited or no access to rehabilitation and/or remedial interventions. As such, this longitudinal cohort study aims to explore the course of TBI impact, one-year post injury, on the cognitive functioning of a pediatric sample of Latin American children from Mexico, between 7 to 17 years of age, who did not receive cognitive rehabilitation.

\section{Method}

\subsection{Participants}

Forty-six children with TBI and 46 healthy controls were recruited from Guadalajara, Mexico. Inclusion criteria for TBI patients were: 1) at the time of the evaluation, have a diagnosis of TBI confirmed by clinical history or laboratory tests (i.e., MRI), 2) have had an alteration of consciousness documented by the Glasgow scale with a score $<15$ during the first 24 hours of being admitted to the hospital, 3) being between 7 and 17 years old at the time of trauma, and 4) reading and writing proficiency. Exclusion criteria for this group were: 1) visual, auditory, or sensorial problems, 2) history of neurological alterations, developmental disorders, learning disabilities, psychiatric disorders, and substance and/or alcohol consumption, and 3) history of intellectual disability.

Inclusion criteria for control group participants were: 1) being between 7 and 17 years old at the time of the first evaluation, and 2) reading and writing proficiency. Exclusion criteria were: 1) visual, auditory, or sensorial problems, 2) history of neurological alterations, developmental disorders, learning disabilities, 
Table 1

Group data for demographics

\begin{tabular}{|c|c|c|c|}
\hline & Variables & $\begin{array}{c}\text { TBI group } \\
(n=46) \\
\text { Median (SD), Range }\end{array}$ & $\begin{array}{c}\text { Control group } \\
(n=46) \\
\text { Median (SD), Range }\end{array}$ \\
\hline \multicolumn{2}{|l|}{ Age (years) } & $10(2.71), 7-15$ & 10 (2.58), 7-15 \\
\hline \multicolumn{2}{|c|}{ Education (years) } & $4(2.13), 1-8$ & $5(2.06), 1-8$ \\
\hline \multicolumn{2}{|c|}{ Glasgow Coma Scale } & $\begin{array}{c}11(2.75), 5-15 \\
n(\%)\end{array}$ & $\begin{array}{l}\text { N.A. } \\
n(\%)\end{array}$ \\
\hline \multirow[t]{2}{*}{ Gender } & Men & $31(67.4 \%)$ & $34(73.9 \%)$ \\
\hline & Women & $15(32.6 \%)$ & $12(26.1 \%)$ \\
\hline \multirow[t]{3}{*}{ TBI severity } & Mild & $10(21.7 \%)$ & N.A. \\
\hline & Moderate & $21(45.7 \%)$ & N.A. \\
\hline & Severe & $15(32.6 \%)$ & N.A. \\
\hline \multirow[t]{5}{*}{ TBI cause } & Falls & $27(58.7 \%)$ & N.A. \\
\hline & Road traffic accidents & $16(34.8 \%)$ & N.A. \\
\hline & Violence & $1(2.2 \%)$ & N.A. \\
\hline & Sports & $1(2.2 \%)$ & N.A. \\
\hline & Unknown & $1(2.2 \%)$ & N.A. \\
\hline
\end{tabular}

Note. N.A. = Not applicable.

psychiatric disorders, and substance and/or alcohol consumption, and 3) history of intellectual disability. There were no missing data at 3 or 6 months for both groups. However, 16 TBI participants were missing data at the final follow-up evaluation. Sociodemographic characteristics of the sample are presented on Table 1.

\subsection{Measures}

Sociodemographic information (i.e., gender, age, school grade, parent level of education) was collected using a researcher-created questionnaire and, in the case of patients, additional TBI-related information was collected (i.e., Glasgow Coma Scale, TBI severity, and TBI cause). A comprehensive neuropsychological assessment was also performed using the tests below.

Spanish Version of Wechsler Intelligence Scale for Children-IV (WISC-IV; Wechsler \& Corral, 2007). Designed to measure overall intellectual ability in children between the ages of 6 and 16. The WISCIV is individually administered and contains 10 core subtests with five supplemental subtests. These are summed up to four indexes (Verbal Comprehension, Perceptual Reasoning, Working Memory, and Processing Speed), and one Full Scale Intelligence Quotient (FSIQ).

Rey-Osterrieth Complex Figure (ROCF; Rey, 2009). Designed to measure visuo-constructional ability and visual memory, the ROCF consists of two parts. In the first part (Copy), participants are presented with a complex figure (Figure $\mathrm{A}$ in this study), which contains 18 different elements, and are instructed to copy it on a blank paper. In the second part (Immediate Recall), participants are asked to reproduce the figure from memory following a 3minute delay. Two scores are obtained: ROCF copy and ROCF memory.

Stroop Color-Word Interference Test (Stroop; Golden, 2007). Designed to measure selective attention and cognitive flexibility. It consists of 3 pages, each of them with 100 stimuli organized in five columns. In the first page (Word part), participants are asked to read color-words printed in black ink in 45 seconds. In the second page (Color part), participants are requested to name the ink color of each stimuli (a series of X) in 45 seconds. Lastly, in the third page (Interference), participants must name the color of the ink in 45 seconds, and avoid reading the word, which corresponds to the name of another color. Four scores are obtained: total number of words, total number of colors, total number of word-color, and interference.

Rey Auditory Verbal Learning Test (RAVLT; Schmidt, 1996). It is used to analyze learning and retention capacity. RAVLT has two word-lists. List A consists of 15 unrelated words. The score awarded for each trial is the total number of words remembered. The total score is the sum of the successes of the 5 trials. The participant is then asked to repeat all words remembered from List A following a 30minute delay. Finally, the recognition list, consists of 30 words that includes all 15 words from List A plus 15 new words. The subject must indicate whether or not the word heard was in List A. 
Peabody Picture Vocabulary Test-III (PPVT-III; Dunn, Dunn, \& Arribas, 2010). Designed to measure receptive vocabulary ability in individuals between the ages of 2 and a half and 90. It consists of 192 test sheets organized according to difficulty. Each test sheet includes 4 black and white images, and participants are asked to select the image that best corresponds to the word prompted by the evaluator. The sum of all correct responses composes the total score.

Trail Making Test (TMT; Reitan, 1992). Designed to measure visual attention, motor speed, cognitive flexibility, and task alternation. It is composed of two parts. In Part A, participants are instructed to connect numbers $(1-15)$ in ascending order. In Part B, participants are asked to alternate between numbers $(1-15)$ and letters $(\mathrm{A}-\mathrm{P})$; as in Part A, the participant draws lines alternating between numbers and letters in ascending pattern (i.e., 1-A-2-B-3-C, etc.). The total score is the number of seconds needed to complete each task. For this study, a limit of $90 \mathrm{sec}-$ onds for TMT-A, and 300 seconds for TMT-B was used.

\subsection{Procedure}

The study was initially approved by the ethics committee of the Fray Antonio Alcalde Hospital of Guadalajara, Mexico. Medical history of children admitted to the neuropediatric and neurosurgery units with a TBI diagnosis was reviewed to select those children that met inclusion criteria. Once selected, parents and/or guardians of children who met inclusion criteria were contacted and invited to participate following a detailed overview about the purpose of the study. Three months following the child's TBI diagnosis, each parent and/or guardian was scheduled for an initial appointment at the hospital to review and provide consent for each child to participate in the study. After informed consent was given and signed, children completed a sociodemographic questionnaire and a comprehensive neuropsychological testing battery to measure different domains of cognitive function including intelligence, attention, memory, processing speed, and EF. Children repeated the same neuropsychological evaluation at 6 and 12 months following the initial evaluation.

Regarding the control group, participants were recruited from the Miguel Hidalgo Educational Center number 23, an educational center located near the hospital where the study was conducted. A meeting was held with the center's teachers to identify children who met sociodemographic characteristics (age, gender, socio-economic status, and education level) like the TBI group, and that also met the study's inclusion criteria. Parents of children who met inclusion criteria were invited to participate following a review of the study's objective. Parents who agreed to participate were provided with informed consent. Once the signed consent was received, a socio-demographic questionnaire and neuropsychological test battery similar to the TBI group was administered. Participants from the control group were also followed at 6 and 12 months, at which time they repeated the same neuropsychological assessment.

All neuropsychological testing and scoring were completed by a neuropsychology master level student under the direct supervision of a doctor of neuropsychology.

\subsection{Data analyses}

Statistical analyses were conducted using the Statistical Package for Social Sciences (SPSS) version 20.0 (SPSS Inc., Chicago, IL). To determine whether children with TBI and healthy controls differed significantly in demographic characteristics, participants' $t$-tests were run for continuous demographic variables and chi-square tests for categorical variables.

Sixteen hierarchical linear models (HLMs) were performed to examine whether linear trajectories of 16 raw scores of different cognitive measures differed over 3, 6, and 12 months between children with TBI and controls. Group (TBI vs. control), time, and the time by group interaction term were entered simultaneously as fixed effects into the HLMs. All continuous predictor variables were centered subtracting the mean from each continuous predictor, and all categorical predictors were given a reference point of 0 before being entered into the HLM. The different cognitive measures scores at each of the three time points were entered into the 16 HLMs as the dependent variable. Independent variables that were not statistically significant in the HLM were removed, and a reduced model was fitted.

The HLM used full information maximum likelihood estimation (FIML) to account for missing data, which allows participants with missing data points to be retained in the HLM. Thus, HLM is more robust than repeated measures analyses of variance or regressions. 
Statistically significant fixed main or interaction effects on cognitive measure trajectories were graphed across each of the three time points. Main effects would indicate that different cognitive measures varied over time as a function of the predictor variable (group or time), and significant interaction effects would indicate that trajectories changed differentially over time as a function of participant group.

\section{Results}

\subsection{Preliminary analysis}

There were no statistically significant differences between children with TBI and healthy controls across the sociodemographic variables ( $p$ 's $>.05$; Table 1). None of the demographic variables were entered as covariates into the proceeding analyses because the lack of significant differences in sociodemographic variables.

\subsection{Cognitive measures trajectories}

\subsubsection{Wechsler Intelligence Scale for Children-IV Trajectories}

The final five HLMs models, as well as their bweights and $p$-values appear in Table 2 .

Verbal Comprehension Index (VCI) and Perceptual Reasoning Index (PRI). The first two HLMs with VCI and PRI as the dependent variables produced significant effects for time $\mathrm{x}$ group interaction
( $p$ 's $<0.01$ ), suggesting that VCI in the TBI group increased over time compared to the lack of change in the healthy control group. Moreover, the PRI in the TBI group remains stable over time while the control group increase from 3 to 6 months.

Working Memory Index (WMI). The HLM with WMI as the dependent variable showed a significant effect for Group, suggesting that the healthy control group had higher scores over time than the TBI group. There were no significant effects for time or the time $\mathrm{x}$ group interaction.

Processing Speed Index (PSI) and Intelligence Quotient (IQ). In the two HLMs with PSI and IQ as dependent variables, statistically significant time and group main effects appeared ( $p$ 's $<0.001$ ), so that both groups increased their scores over time, though the TBI group scored lower in all time points compared to healthy control group. There were no significant effects for time $\mathrm{x}$ group interaction. Figures 1-5 show WISC-IV scores trajectories.

\subsubsection{Rey-Osterrieth Complex Figure Trajectories}

The final two HLMs models, as well as their bweights and $p$-values appear in Table 3.

Copy and Memory trajectories. The two HLMs with the copy and memory score as the dependent variables showed significant effects for time and group ( $p$ 's $<0.01$ ), so that both groups increased their scored over time, though the healthy control group scored higher compared to the TBI group in each time point.

Table 2

Predictors of each WISC-IV scores trajectories at 3, 6 and 12 months after the TBI

\begin{tabular}{llccccccc}
\hline $\begin{array}{l}\text { Outcome } \\
\text { variables }\end{array}$ & Predictors & $\begin{array}{c}\text { b- } \\
\text { weight }\end{array}$ & $\begin{array}{c}\text { Std. } \\
\text { Error }\end{array}$ & df & $t$ & $p$-value & \multicolumn{2}{c}{$\begin{array}{c}95 \% \text { Confidence } \\
\text { interval }\end{array}$} \\
\hline VCI & Intercept & 82.85 & 1.65 & 175.50 & 50.04 & $<0.001$ & 79.59 & 86.12 \\
& Group & 22.65 & 2.01 & 200.82 & 11.29 & $<0.001$ & 18.69 & 26.60 \\
& Time & 4.18 & 1.23 & 207.15 & 3.39 & 0.001 & 1.75 & 6.60 \\
& Time $\times$ Group & -4.58 & 1.72 & 200.82 & -2.66 & 0.008 & -7.97 & -1.18 \\
\hline PRI & Intercept & 85.88 & 1.62 & 175.07 & 52.98 & $<0.001$ & 82.68 & 89.08 \\
& Group & 12.92 & 1.95 & 200.51 & 6.64 & $<0.001$ & 9.081 & 16.76 \\
& Time & 0.57 & 1.19 & 206.66 & 0.48 & 0.632 & -1.78 & 2.93 \\
& Time $\times$ Group & 3.48 & 1.67 & 200.51 & 2.08 & 0.038 & 0.19 & 6.77 \\
\hline WMI & Intercept & 79.19 & 1.06 & 83.26 & 74.61 & $<0.001$ & 77.08 & 81.30 \\
& Group & 10.88 & 1.08 & 199.39 & 10.03 & $<0.001$ & 8.74 & 13.02 \\
\hline PSI & Intercept & 73.17 & 1.66 & 178.51 & 44.15 & $<0.001$ & 69.90 & 76.44 \\
& Group & 24.59 & 1.67 & 199.79 & 14.69 & $<0.001$ & 21.29 & 27.89 \\
& Time & 4.16 & 1.09 & 217.24 & 3.81 & $<0.001$ & 2.01 & 6.31 \\
\hline IQ & Intercept & 75.87 & 1.32 & 138.50 & 57.24 & $<0.001$ & 73.25 & 78.49 \\
& Group & 22.05 & 1.20 & 200.89 & 18.37 & $<0.001$ & 19.68 & 24.41 \\
& Time & 3.31 & 0.79 & 212.98 & 4.19 & $<0.001$ & 1.75 & 4.86 \\
\hline
\end{tabular}




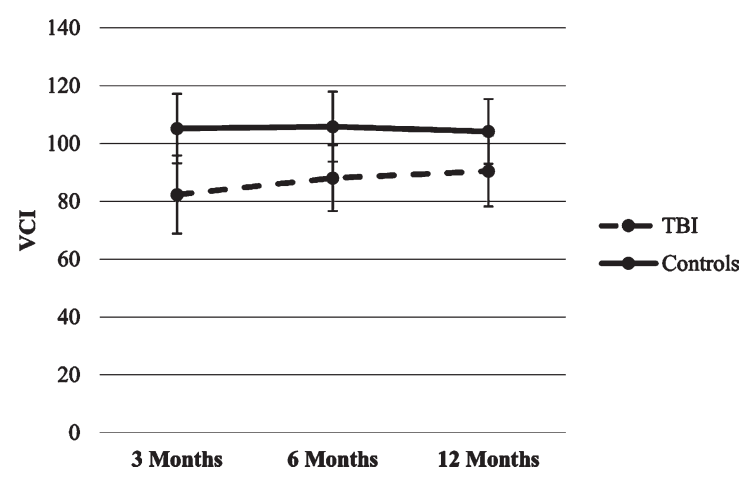

Fig. 1. Trajectories of WISC-IV VCI score.

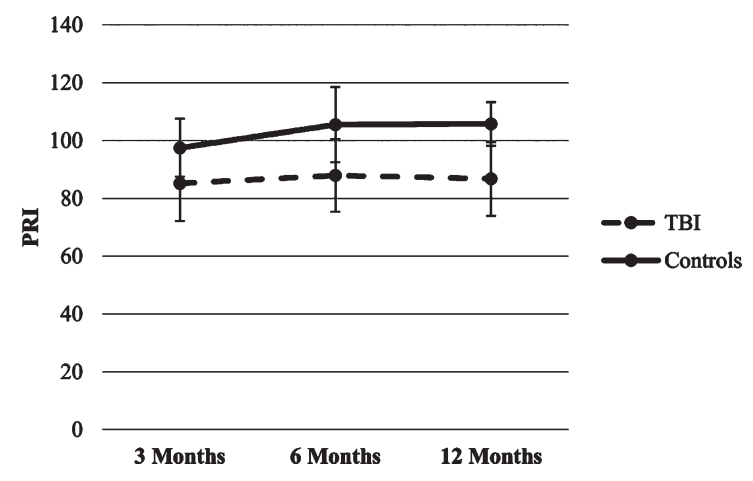

Fig. 2. Trajectories of WISC-IV PRI score.

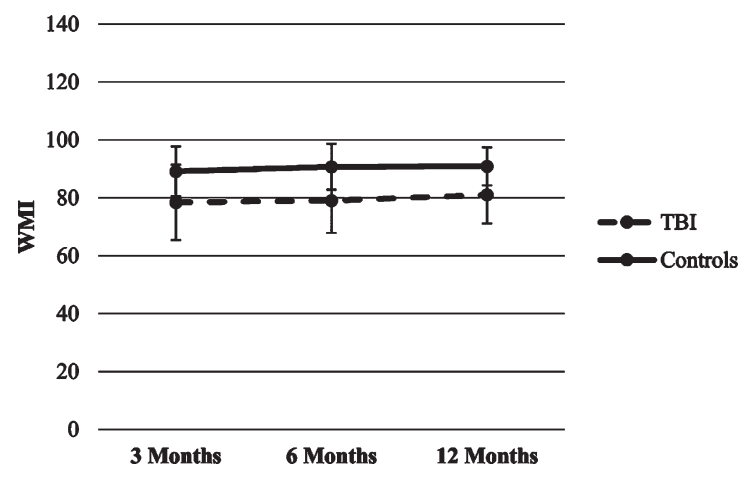

Fig. 3. Trajectories of WISC-IV WMI score.

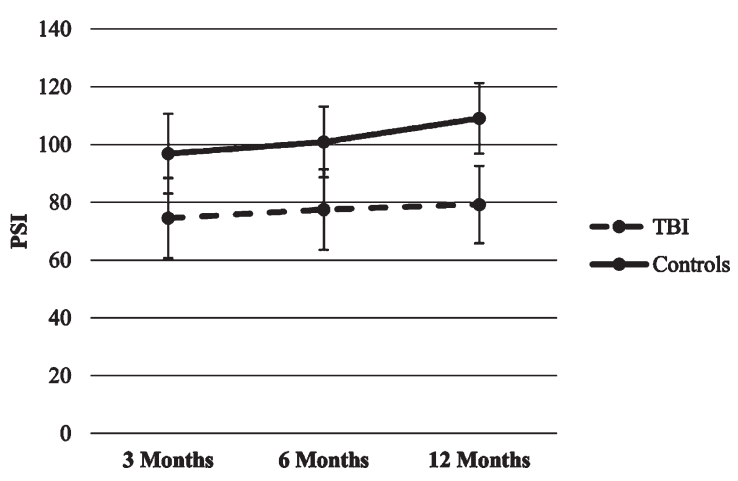

Fig. 4. Trajectories of WISC-IV PSI score.

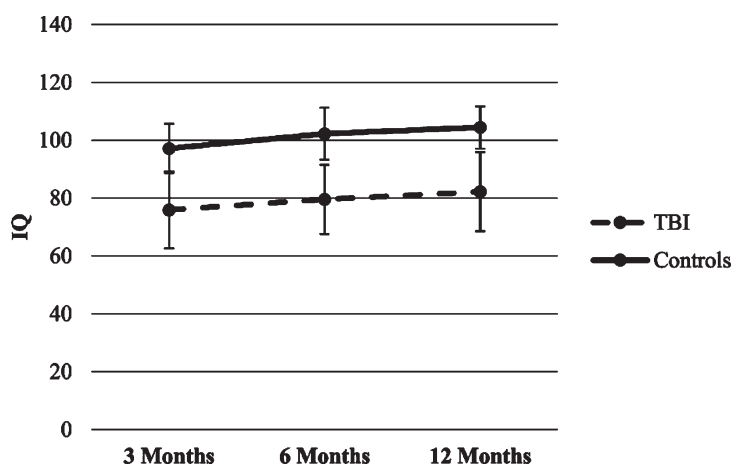

Fig. 5. Trajectories of WISC-IV IQ score.

There were no significant effects for time $\mathrm{x}$ group interaction. Figures 6 and 7 show ROCF scores trajectories.

\subsubsection{Stroop Color-Word Interference Test Trajectories}

The final four HLMs models, as well as their bweights and $p$-values appear in Table 4.

Word. The HLM with Word score as the dependent variable produced a significant main effect for group $(p<.001)$, suggesting that TBI group scored lower over time compared to the healthy control group.

Table 3

Predictors of each ROCF scores trajectories at 3, 6 and 12 months after the TBI

\begin{tabular}{llccccccc}
\hline $\begin{array}{l}\text { Outcome } \\
\text { variables }\end{array}$ & Predictors & $\begin{array}{c}\mathrm{b}- \\
\text { weight }\end{array}$ & $\begin{array}{c}\text { Std. } \\
\text { Error }\end{array}$ & df & $t$ & $p$-value & \multicolumn{2}{c}{$\begin{array}{c}\text { 95\% Confidence } \\
\text { interval }\end{array}$} \\
\hline Copy & Intercept & 15.72 & 0.85 & 118.56 & 18.52 & $<0.001$ & 14.04 & 17.40 \\
& Group & 12.34 & 0.73 & 197.86 & 16.93 & $<0.001$ & 10.90 & 13.77 \\
& Time & 1.42 & 0.48 & 208.79 & 2.96 & 0.003 & 0.48 & 2.37 \\
\hline Memory & Intercept & 6.86 & 0.77 & 129.602 & 8.848 & $<0.001$ & 5.33 & 8.40 \\
& Group & 10.42 & 0.69 & 198.16 & 15.05 & $<0.001$ & 9.05 & 11.78 \\
& Time & 2.92 & 0.45 & 210.34 & 6.40 & $<0.001$ & 2.09 & 3.81 \\
\hline
\end{tabular}




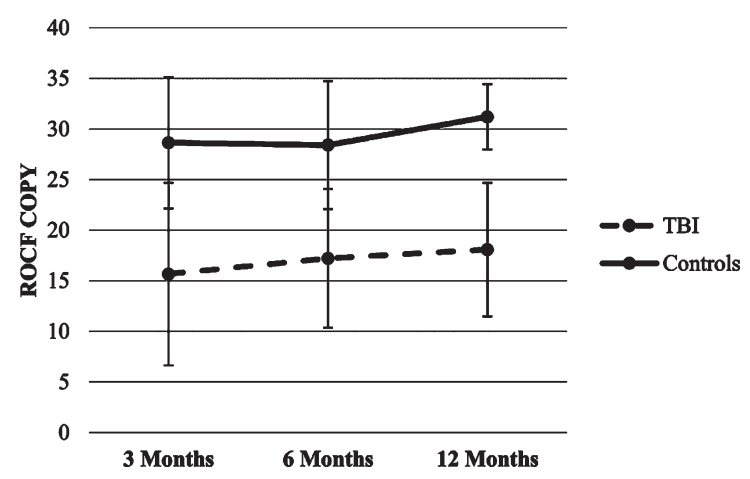

Fig. 6. Trajectories of ROCF Copy score.

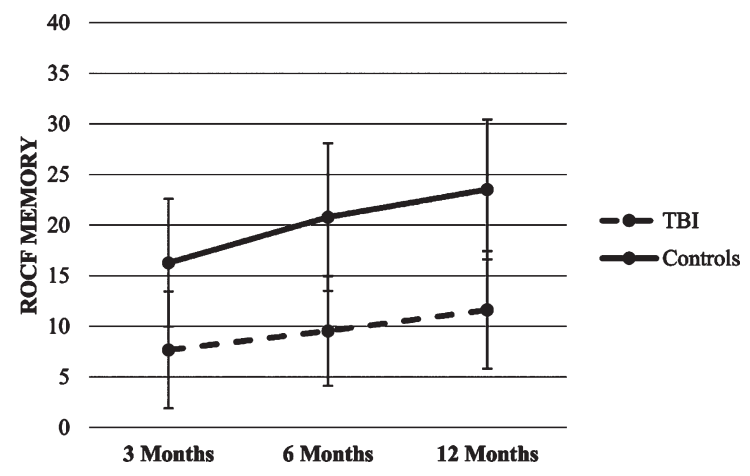

Fig. 7. Trajectories of ROCF Memory score.

There were no significant effects for time or the time $\mathrm{x}$ group interaction.

Color and Color-Word. The two HLMs with Color and Color-Word scores as dependent variables showed significant effects for time $\mathrm{x}$ group interaction ( $p$ 's $<0.01$ ), suggesting that both scores in the TBI group increased over time compared to the stability of scores in the healthy control group.

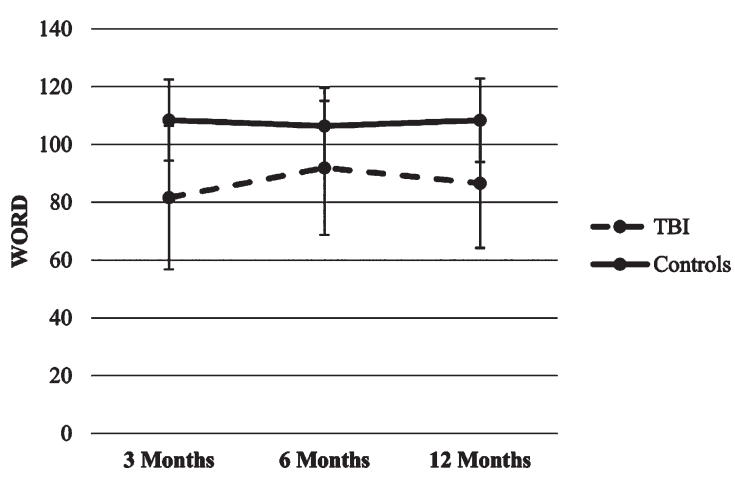

Fig. 8. Trajectories of Stroop Word score.

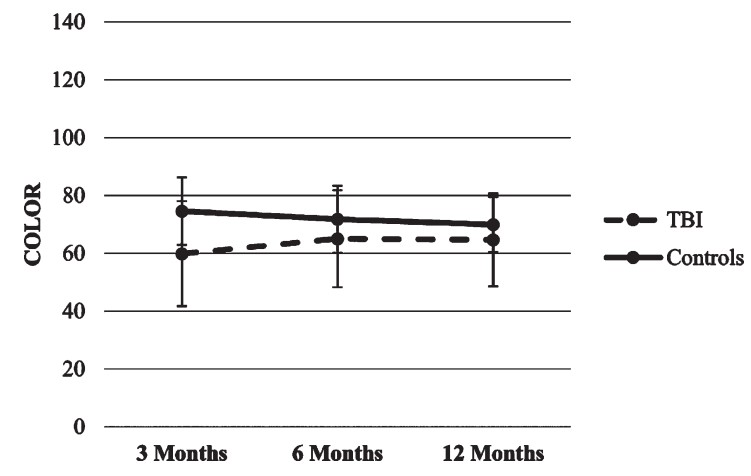

Fig. 9. Trajectories of Stroop Color score.

Interference. No significant predictors were found for Stroop Interference score. Figures 8-10 show Stroop scores trajectories.

\subsubsection{Rey auditory verbal learning test trajectories}

The final two HLMs models, as well as their bweights and $p$-values appear in Table 5.

Table 4

Predictors of each Stroop scores trajectories at 3,6 and 12 months after the TBI

\begin{tabular}{llccccccc}
\hline $\begin{array}{l}\text { Outcome } \\
\text { variables }\end{array}$ & Predictors & $\begin{array}{c}\text { b- } \\
\text { weight }\end{array}$ & $\begin{array}{c}\text { Std. } \\
\text { Error }\end{array}$ & & df & $t$ & $p$-value & \multicolumn{2}{c}{$\begin{array}{c}95 \% \text { Confidence } \\
\text { interval }\end{array}$} \\
\hline Word & Intercept & 86.93 & 2.12 & 80.35 & 40.96 & $<0.001$ & 82.71 & 91.15 \\
& Group & 20.94 & 2.11 & 199.27 & 9.93 & $<0.001$ & 16.78 & 25.10 \\
\hline Color & Intercept & 60.67 & 2.00 & 136.91 & 30.26 & $<0.001$ & 56.70 & 64.63 \\
& Group & 13.72 & 2.20 & 198.19 & 6.24 & $<0.001$ & 9.38 & 18.05 \\
& Time & 2.71 & 1.35 & 202.85 & 2.01 & 0.046 & 0.05 & 5.38 \\
& Time $\times$ Group & -4.97 & 1.88 & 198.19 & -2.64 & 0.009 & -8.69 & -1.26 \\
\hline Word-Color & Intercept & 36.46 & 1.46 & 186.54 & 24.89 & $<0.001$ & 33.57 & 39.35 \\
& Group & 11.57 & 1.81 & 198.20 & 6.37 & $<0.001$ & 7.99 & 15.16 \\
& Time & 3.18 & 1.11 & 205.44 & 2.86 & .005 & 0.99 & 5.37 \\
& Time $\times$ Group & -4.31 & 1.56 & 198.20 & -2.77 & .006 & -7.38 & -1.24 \\
\hline
\end{tabular}




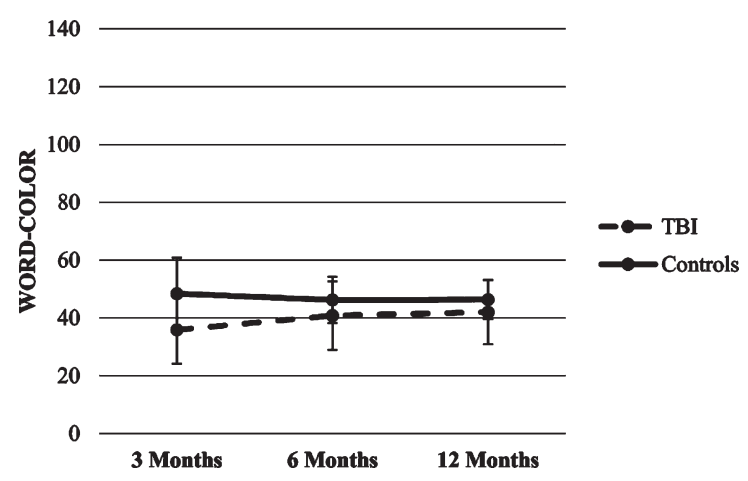

Fig. 10. Trajectories of Stroop Word-color score.

Learning. The HLM with Learning as dependent variable showed a significant effect for time $\mathrm{x}$ group interaction $(p<.01)$, suggesting that TBI group increased its score over time compared to the lack of change in the healthy control group.

Memory. The HLM with Memory as the dependent variable produced a significant main effect for group $(p<.001)$, suggesting that TBI group scored lower in each time point compared to the healthy control group. There were no significant effects for time or the time $\mathrm{x}$ group interaction.

Figures 11 and 12 show RAVLT scores trajectories.

\subsubsection{Peabody Picture Vocabulary Test-III Trajectories}

The final HLM model, as well as its b-weights and $p$-values appear in Table 6.

The HLM with PPVT-III total score as the dependent variable showed significant effects for time and group ( $p$ 's $<0.001)$, so that both groups increased their scored over time, although the healthy control group scored higher compared to the TBI group in each time point. There were no significant effects for time $\mathrm{x}$ group interaction. Figure 13 shows PPVT-III score trajectory.

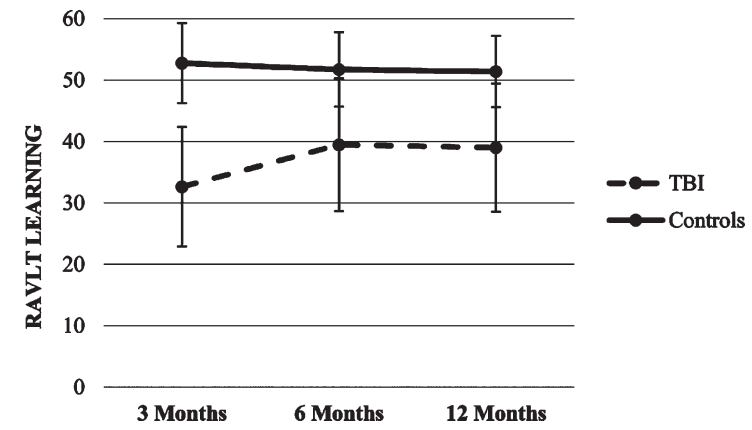

Fig. 11. Trajectories of RAVLT Learning score.

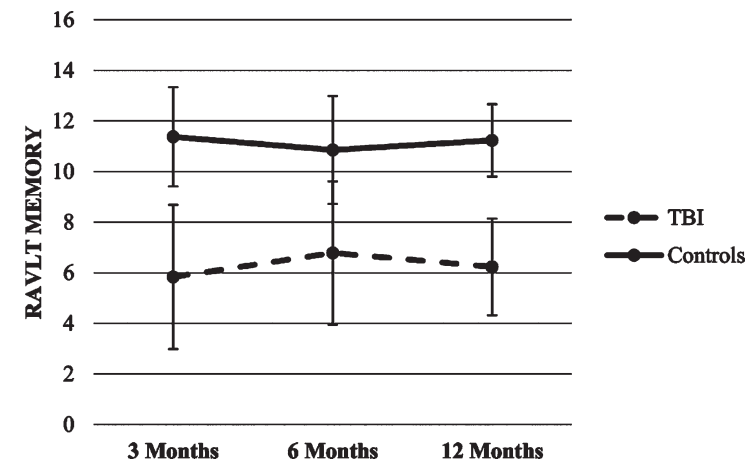

Fig. 12. Trajectories of RAVLT Memory score.

\subsubsection{Trail Making Test Trajectories}

The final two HLMs models, as well as their bweights and $p$-values appear in Table 7.

TMT A and B trajectories. The two HLMs with TMT $A$ and $B$ total score as the dependent variables showed significant effects for time and group ( $p$ 's $<0.001$ ), so that both groups decreased the time needed to complete the task over time, although the healthy control group was faster compared with the TBI group in each time point. There were no significant effects for time $\mathrm{x}$ group interaction. Figures 14 and 15 show TMT scores trajectories.

Table 5

Predictors of each RAVLT scores trajectories at 3, 6 and 12 months after the TBI

\begin{tabular}{llccccccc}
\hline $\begin{array}{l}\text { Outcome } \\
\text { variables }\end{array}$ & Predictors & $\begin{array}{c}\mathrm{b} \text { - } \\
\text { weight }\end{array}$ & $\begin{array}{c}\text { Std. } \\
\text { Error }\end{array}$ & & $\mathrm{df}$ & $t$ & $p$-value & \multicolumn{2}{c}{$\begin{array}{c}95 \% \text { Confidence } \\
\text { interval }\end{array}$} \\
\hline Learning & Intercept & 33.70 & 1.16 & 212.94 & 28.90 & $<0.001$ & 31.40 & 36.00 \\
& Group & 18.90 & 1.52 & 199.55 & 12.42 & $<0.001$ & 15.90 & 21.90 \\
& Time & 3.63 & 0.93 & 208.31 & 3.90 & $<0.001$ & 1.80 & 5.46 \\
& Time $\times$ Group & -4.19 & 1.30 & 199.55 & -3.21 & 0.002 & -6.76 & -1.62 \\
\hline Memory & Intercept & 6.29 & 0.22 & 122.27 & 28.30 & $<0.001$ & 5.85 & 6.73 \\
& Group & 4.85 & 0.28 & 202.75 & 17.16 & $<0.001$ & 4.29 & 5.41 \\
\hline
\end{tabular}


Table 6

Predictors of each PPVT-III scores trajectories at 3, 6 and 12 months after the TBI

\begin{tabular}{lccccccc}
\hline Predictors & $\begin{array}{c}\mathrm{b}- \\
\text { weight }\end{array}$ & $\begin{array}{c}\text { Std. } \\
\text { Error }\end{array}$ & df & $t$ & $p$-value & \multicolumn{2}{c}{$\begin{array}{c}95 \% \text { Confidence } \\
\text { interval }\end{array}$} \\
\hline Intercept & 84.26 & 2.07 & 84.51 & 40.75 & $<0.001$ & 80.15 & 88.38 \\
Group & 12.37 & 1.45 & 198.25 & 8.55 & $<0.001$ & 9.51 & 15.22 \\
Time & 4.77 & 0.96 & 204.50 & 4.96 & $<0.001$ & 2.87 & 6.66 \\
\hline
\end{tabular}

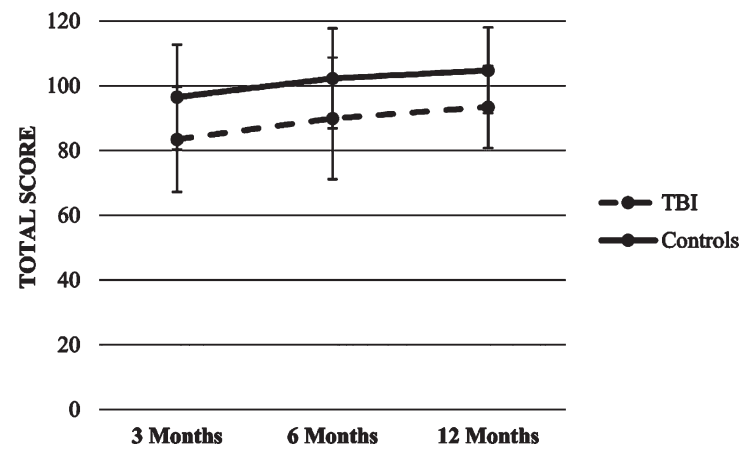

Fig. 13. Trajectory of PPVT-III score.

\section{Discussion}

To the best of our knowledge this study is the first to explore the cognitive function trajectories of a group of Mexican children between the ages of 6 and 17 during the first-year post TBI compared to a healthy control group. Results indicate that in both group cognitive performance increased over time, however children with TBI scored significantly lower at each time point compare to the healthy control group.

Results from this study are commensurate to the existing literature findings regarding changes in cognitive ability in children with TBI during the first-year post injury, with working memory (Gorman et al., 2017; Krasny-Pacini et al., 2017; Van Beek et al., 2015), attention and inhibition (Krasny-Pacini et al., 2017; Treble-Barna et al., 2017), and language
TMT-A

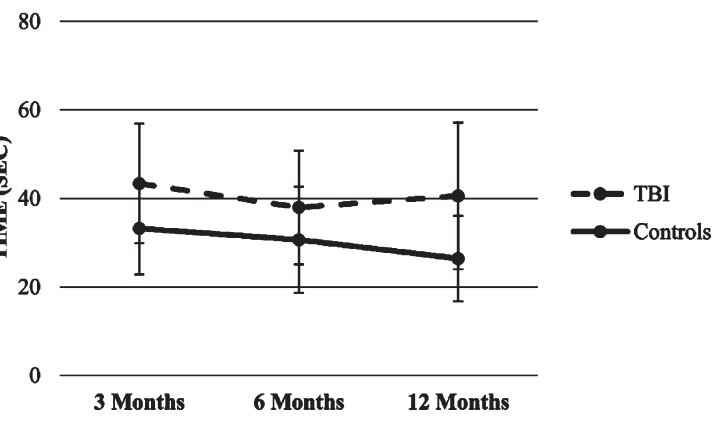

Fig. 14. Trajectory of TMT-A score.

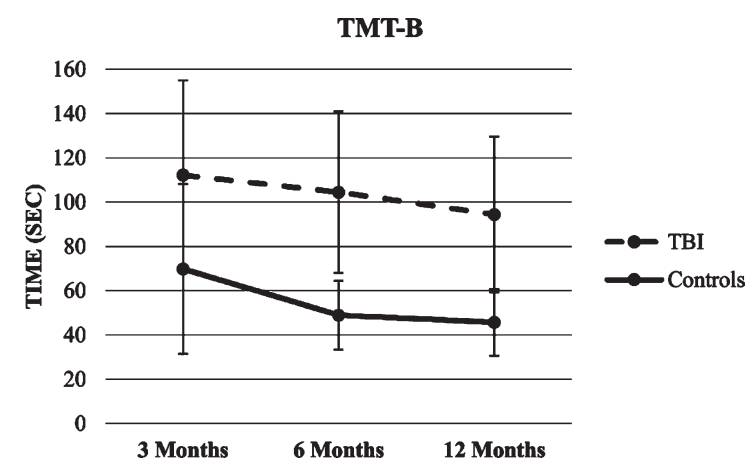

Fig. 15. Trajectory of TMT-B score.

(Ewing-Cobbs et al., 1997; Jonsson et al., 2013; Pomerleau et al., 2012; Ryan et al., 2015) as the most vulnerable cognitive domains. In detail, results

Table 7

Predictors of each TMT scores trajectories at 3, 6 and 12 months after the TBI

\begin{tabular}{llccccccc}
\hline $\begin{array}{l}\text { Outcome } \\
\text { variables }\end{array}$ & Predictors & $\begin{array}{c}\text { b- } \\
\text { weight }\end{array}$ & $\begin{array}{c}\text { Std. } \\
\text { Error }\end{array}$ & df & $t$ & $p$-value & \multicolumn{2}{c}{$\begin{array}{c}95 \% \text { Confidence } \\
\text { interval }\end{array}$} \\
\hline TMT - A & Intercept & 42.99 & 1.56 & 126.24 & 27.57 & $<0.001$ & 39.91 & 46.08 \\
& Group & -10.06 & 1.36 & 199.47 & -7.37 & $<0.001$ & -12.75 & -7.37 \\
& Time & -3.03 & 0.90 & 210.69 & -3.37 & 0.001 & -4.80 & -1.26 \\
\hline TMT - B & Intercept & 114.60 & 4.03 & 146.75 & 28.43 & $<0.001$ & 106.64 & 122.57 \\
& Group & -48.93 & 3.77 & 199.24 & -12.97 & $<0.001$ & -56.36 & -41.49 \\
& Time & -11.62 & 2.47 & 213.05 & -4.69 & $<0.001$ & -16.50 & -6.74 \\
\hline
\end{tabular}


from this study evidence a significant lower performance in working memory (TMT-B and WMI), attention (TMT-A, Stroop Word, and Stroop Color), and language (PPVT and VCI) in the TBI group, in addition to processing speed (PSI), memory and learning (ROCF and RAVLT), and IQ.

On the other hand, some results from this study differ from previous research findings. For instance, Beauchamp et al. (2011) explored the EF of a group of 40 adolescents with mild, moderate, and severe TBI 10 years post injury, and compared it to the performance of a healthy control group of 19 adolescents. The authors reported that adolescents with mild to moderate TBI evidenced age-appropriate EF abilities, while those with severe TBI demonstrated significant deficits. In contrast, the present study found that the TBI group demonstrated below average performance on measures of EF over time. Such discrepancy could be attributed to many factors. Unlike the study of Beauchamp et al. (2011), where the evaluation was completed 10 years post injury, the present study assessed children at 3, 6, and 12 months post TBI, thus it stands to reason that deficits are more evidently observed immediately after the injury. Furthermore, children in the study by Beauchamp et al. (2011) were between 1 and 7 years of age at the time of the injury, whereas the age of the children in the present study ranged between 7 and 17 . Given that the children in the study by Beauchamp et al. (2011) were younger at the time of injury when compared to the older age range of children from the present study, it is possible that recovery may have been influenced by neuroplasticity. On the other hand, it must be borne in mind that EF continue to develop throughout childhood and adolescence, so there is a possibility that the children in the Beauchamp study show no alterations compared to the present study's children since their EF are more developed. Lastly, Beauchamp et al. (2011) regarded attentional control, cognitive flexibility, goal setting, and information processing as $\mathrm{EF}$, whereas the present study treated information processing and attention as independent processes from EF.

In another study, Crowe et al. (2013) evaluated the information processing of a group of 35 children with mild, moderate, and severe TBI, and compared it to 20 children from a healthy control group. Although significant performance differences were observed on tasks of inhibition control, the performance on tasks of information processing was similar between both the TBI and control groups. In contrast, children in the TBI group of the present study evidenced significantly lower scores in the PSI of the WISC-III when compared to the performance of the control group on all three testing sessions. Such discrepancies in scores may be due to a variety of reasons. On one hand, the study by Crowe et al. (2013) was completed 2 years post injury, where, similarly to the findings observed by Beauchamp et al. (2011), a spontaneous recovery is observed, evidenced in the absence or a decrease in injury-related cognitive deficits over time. Another important factor possibly impacting the difference in scores is the age at the time of injury, given that children from the study by Crowe et al. (2013) were between 3 weeks and 2 and half years of age at the time of their TBI. Finally, the neuropsychological measures used to assess processing speed differ between both studies, where Crowe et al. (2013) only utilized the Coding subtest from the WPPSI-III, while the present study included the Coding, Symbol Search, and Cancellation subtests to measure the same cognitive domain.

In terms of the spontaneous recovery hypothesis, other authors such as Anderson et al. (2012a) also reached a similar conclusion. These group of researchers assessed a group of 76 children with mild, moderate, and severe TBI at 12 and 30 months, and then 10 years post injury. Their findings indicated that, although processing speed deficits were initially observed in children with TBI, their development and functioning appeared adequate after two years following the injury. While results from the present study indicate that the TBI group's performance was lower when compared to the healthy control group, performance improvement is observed in some of the tasks over time. Moreover, when we take into consideration that all neuropsychological evaluations were completed during the first-year post injury, and without rehabilitative intervention, it seems reasonable to interpret the outcome in terms of a spontaneous recovery. Nevertheless, given that all participants were evaluated using the same testing measures at the time of each evaluation, and that children from the healthy control group also demonstrated improvement in some of the tasks, it is imperative to consider the learning effect as an influential variable in the children's performance improvement over time. This evidences the need to design and utilize testing measures that offer alternate forms to evaluate the same construct (i.e., verbal memory measures that provide different word lists).

An important aspect to consider is that in the majority of the studies (i.e., Anderson et al., 2012a; Arroyos-Jurado et al., 2006; Beauchamp et al., 2011; 
Catroppa et al., 2008; Fay et al., 2009; Ryan et al., 2015; Treble-Barna et al., 2017), TBI severity and age at the time of injury were both variables that impacted results, where higher TBI severity paired with younger age at the time of injury yielded lower performance. However, an analysis of the relationship between these two variables could not be conducted due to the small sample size of the present study.

Results from this study have important research and clinical implications. Primarily, although children from the TBI group evidenced a slight improvement in their scores on cognitive measures over time, such scores, on the vast majority of tasks, fell significantly below those of the control group. As such, it is imperative for clinicians to evaluate the cognitive function of children with TBI during the first-year post injury and provide cognitive rehabilitation interventions as needed. Secondly, results from the present study also suggests the need for clinicians to work closely with teachers and other educators to provide adequate school accommodations that are individually tailored for each child. Moreover, it is important to conduct research to identify not only cognitive but also possible short term and long-term emotional and behavioral sequelae in children with TBI one-year post injury and understand their implications in the children's ability to adequately reintegrate their social, academic, and family life. Lastly, results from this study make it imperative to conduct further research to identify which variables play a role in the recovery or improvement of the cognitive function of children with TBI, as well as to determine the efficacy of implementing rehabilitative neuropsychology programs during the acute phase of TBI.

Despite the importance of the present study, results should be interpreted in the context of the following limitations. 1) The sample size included a group of 46 children with TBI and a control group of 46 healthy children, resulting in a limited ability to generalize these findings. 2) All participants were from the city of Guadalajara, Mexico; thus, the results cannot be extrapolated to patient groups from other regions in Mexico, or other Latin American countries of different sociodemographic characteristics. For example, different levels of socioeconomic status between regions can play a relevant role in the cognitive function of children due to limited or poor access to education, and even malnutrition because of limited resources that may impact adequate brain development. 3) The sample was collected from a public hospital in the city of Guadalajara, and as such, results from this study are not applicable to children with TBI who have been cared for at a private hospital in the same city, given that variability in quality of care may vary and influence the overall impact of TBI. 4) The age of children included in the present study ranged between 7 and 17 years. As such, results cannot be generalized to younger children. 5) Children evaluated in this study did not receive cognitive rehabilitation following the TBI; thus, the results are not applicable to children who have received prior rehabilitative interventions. Future research should explore the cognitive performance of children who have participated in cognitive rehabilitation following a TBI, and compare it to those children who did not, to evaluate the efficacy of rehabilitative interventions. 6) Individuals with mild TBI typically recover within the first month after the injury, however, the decision was made to combine participants with mild and moderate TBI into the same group because a) some studies have found that some children with mild TBI could present deficits even beyond more than one year post injury (Hawley et al., 2004; Hessen, Nestvold, \& Sundet, 2006; Klonoff, Clark, \& Klonoff, 1993; McKinlay et al., 2008), and b) the sample size was not big enough to permit analysis by injury severity. Future studies should stratify by injury severity in order to reduce the variability and improve the detection of differences in individual trajectories. 7) In this study, participants were only followed for the first year post TBI. Although improvement in some areas of cognitive function was observed, a more thorough trace should be conducted to identify if such improvement disappears or persists over time, given that this could have implications on greater recovery after 12 months post injury.

In conclusion, despite the limitations discussed, the present study contributes significantly to the current literature given that it is the first study to evaluate the cognitive function trajectory of Mexican children with TBI one-year post injury. Findings from this study demonstrated an overall lower performance on children with TBI at each time point when compared to healthy controls on measures of attention, working memory or EF, learning and memory, processing speed, language, perceptual reasoning, visuo-spatial skills, and IQ in all three testing sessions, with gradual improvement over time for both groups. Results also suggest the need to develop rehabilitative programs to improve the cognitive performance of children with TBI, and consequently facilitate their adequate social, academic, and family life reintegration. 


\section{Conflict of interest}

The authors report no conflicts of interest.

\section{References}

Allen, D. N., Leany, B. D., Thaler, N. S., Cross, C., Sutton, G. P., \& Mayfield, J. (2010). Memory and attention profiles in pediatric traumatic brain injury. Archives of Clinical Neuropsychology, 25(7), 618-633.

Anderson, V. A., Catroppa, C., Rosenfeld, J., Haritou, F., \& Morse, S. A. (2000). Recovery of memory function following traumatic brain injury in pre-school children. Brain Injury, 14(8), 679-692.

Anderson, V., \& Catroppa, C. (2007). Memory outcome at 5 years post-childhood traumatic brain injury. Brain injury, 21(13-14), 1399-1409.

Anderson, V., Catroppa, C., Godfrey, C., \& Rosenfeld, J. V. (2012c). Intellectual ability 10 years after traumatic brain injury in infancy and childhood: What predicts outcome? Journal of Neurotrauma, 29(1), 143-153.

Anderson, V., Catroppa, C., Morse, S., Haritou, F., \& Rosenfeld, J. (2001). Outcome from mild head injury in young children: A prospective study. Journal of Clinical and Experimental Neuropsychology, 23(6), 705-717.

Anderson, V., Eren, S., Dob, R., Le Brocque, R., Iselin, G., Davern, T. J.,... \& Kenardy, J. (2012b). Early attention impairment and recovery profiles after childhood traumatic brain injury. The Journal of head trauma rehabilitation, 27(3), 199-209.

Anderson, V., Godfrey, C., Rosenfeld, J. V., \& Catroppa, C. (2012a). 10 years outcome from childhood traumatic brain injury. International journal of developmental neuroscience, 30(3), 217-224

Arroyos-Jurado, E., Paulsen, J. S., Ehly, S., \& Max, J. E. (2006). Traumatic brain injury in children and adolescents: Academic and intellectual outcomes following injury. Exceptionality, 14(3), 125-140.

Beauchamp, M., Catroppa, C., Godfrey, C., Morse, S., Rosenfeld, J. V., \& Anderson, V. (2011). Selective changes in executive functioning ten years after severe childhood traumatic brain injury. Developmental neuropsychology, 36(5), 578-595.

Bellerose, J., Bernier, A., Beaudoin, C., Gravel, J., \& Beauchamp, M. H. (2017). Long-term brain-injury-specific effects following preschool mild TBI: A study of theory of mind. Neuropsychology, 31(3), 229.

Butler, K., Rourke, B. P., Fuerst, D. R., \& Fisk, J. L. (1997). A typology of psychosocial functioning in pediatric closed-head injury. Child Neuropsychology, 3(2), 98-133.

Catroppa, C., Anderson, V. A., Morse, S. A., Haritou, F., \& Rosenfeld, J. V. (2008). Outcome and predictors of functional recovery 5 years following pediatric traumatic brain injury (TBI). Journal of pediatric psychology, 33(7), 707-718.

Chevignard, M. P., Catroppa, C., Galvin, J., \& Anderson, V. (2010). Development and evaluation of an ecological task to assess executive functioning post childhood TBI: The Children's Cooking Task. Brain Impairment, 11(2), 125-143.

Crowe, L. M., Catroppa, C., Babl, F. E., \& Anderson, V. (2013). Executive function outcomes of children with traumatic brain injury sustained before three years. Child Neuropsychology, 19(2), 113-126.

Crowther, J. E., Hanten, G., Li, X., Dennis, M., Chapman, S. B., \& Levin, H. S. (2011). Impairments in learning, memory, and metamemory following childhood head injury. The Journal of head trauma rehabilitation, 26(3), 192-201.

Da Dalt, L., Marchi, A. G., Laudizi, L., Crichiutti, G., Messi, G., Pavanello, L.,... \& Barbone, F. (2006). Predictors of intracranial injuries in children after blunt head trauma. European journal of pediatrics, 165(3), 142-148.

Daneshvar, D. H., Riley, D. O., Nowinski, C. J., McKee, A. C., Stern, R. A., \& Cantu, R. C. (2011). Long-term consequences: Effects on normal development profile after concussion. Physical Medicine and Rehabilitation Clinics, 22(4), 683-700.

Demir, Ö. E., Levine, S. C., \& Goldin-Meadow, S. (2010). Narrative skill in children with early unilateral brain injury: A possible limit to functional plasticity. Developmental Science, 13(4), 636-647.

Dennis, M., Wilkinson, M., Koski, L., \& Humphreys, R. P. (1995). Attention deficits in the long term after childhood head injury. In S. H. Broman \& M. E. Michel (Eds.), Traumatic head injury in children. (pp. 165-187). New York, NY: Oxford University Press.

Dewan, M. C., Mummareddy, N., Wellons III, J. C., \& Bonfield, C. M. (2016). Epidemiology of global pediatric traumatic brain injury: Qualitative review. World neurosurgery, 91, 497-509.

Dunn, LM., Dunn, LM., \& Arribas, D. (2010). PPVT-III Peabody Test de vocabulario en imágenes. Manual. Madrid: TEA Ediciones.

Ewing-Cobbs, L., Barnes, M., Fletcher, J. M., Levin, H. S., Swank, P. R., \& Song, J. (2004). Modeling of longitudinal academic achievement scores after pediatric traumatic brain injury. Developmental neuropsychology, 25(1-2), 107-133.

Ewing-Cobbs, L., Fletcher, J. M., Levin, H. S., Francis, D. J., Davidson, K., \& Miner, M. E. (1997). Longitudinal neuropsychological outcome in infants and preschoolers with traumatic brain injury. Journal of the International Neuropsychological Society, 3(6), 581-591.

Fay, T. B., Yeates, K. O., Wade, S. L., Drotar, D., Stancin, T., \& Taylor, H. G. (2009). Predicting longitudinal patterns of functional deficits in children with traumatic brain injury. Neuropsychology, 23(3), 271.

Fulton, J. B., Yeates, K. O., Taylor, H. G., Walz, N. C., \& Wade, S. L. (2012). Cognitive predictors of academic achievement in young children 1 year after traumatic brain injury. Neuropsychology, 26(3), 314.

Golden, CJ. (2007). Stroop, Test de Colores y Palabras: Manual ( $5^{\circ}$ Edición). Madrid: TEA Ediciones, S.A.

Gorman, S., Barnes, M. A., Swank, P. R., \& Ewing-Cobbs, L. (2017). Recovery of working memory following pediatric traumatic brain injury: A longitudinal analysis. Developmental neuropsychology, 42(3), 127-145.

Hawley, C. A., Ward, A. B., Magnay, A. R., \& Long, J. (2003). Parental stress and burden following traumatic brain injury amongst children and adolescents. Brain injury, 17(1), 1-23.

Hawley, C. A., Ward, A. B., Magnay, A. R., \& Long, J. (2004). Outcomes following childhood head injury: A population study. Journal of Neurology, Neurosurgery \& Psychiatry, 75(5), 737 742.

Hessen, E., Nestvold, K., \& Sundet, K. (2006). Neuropsychological function in a group of patients 25 years after sustaining 
minor head injuries as children and adolescents. Scandinavian journal of psychology, 47(4), 245-251.

Jonsson, C. A., Catroppa, C., Godfrey, C., Smedler, A. C., \& Anderson, V. (2013). Cognitive recovery and development after traumatic brain injury in childhood: A person-oriented, longitudinal study. Journal of neurotrauma, 30(2), 76-83.

Kinsella, G. J., Prior, M., Sawyer, M., Ong, B., Murtagh, D., Eisenmajer, R.,... \& Klug, G. (1997). Predictors and indicators of academic outcome in children 2 years following traumatic brain injury. Journal of the international Neuropsychological Society, 3(6), 608-616.

Kirkwood, M. W., Yeates, K. O., Taylor, H. G., Randolph, C., McCrea, M., \& Anderson, V. A. (2008). Management of pediatric mild traumatic brain injury: A neuropsychological review from injury through recovery. The Clinical Neuropsychologist, 22(5), 769-800.

Klonoff, H., Clark, C., \& Klonoff, P. S. (1993). Long-term outcome of head injuries: A 23 year follow up study of children with head injuries. Journal of Neurology, Neurosurgery \& Psychiatry, 56(4), 410-415.

Krasny-Pacini, A., Chevignard, M., Lancien, S., Escolano, S., Laurent-Vannier, A., De Agostini, M., \& Meyer, P. (2017). Executive function after severe childhood traumatic brain injury-Age-at-injury vulnerability periods: The TGE prospective longitudinal study. Annals of physical and rehabilitation medicine, 60(2), 74-82.

Kuhtz-Buschbeck, J. P., Hoppe, B., Gölge, M., Dreesmann, M., Damm-Stünitz, U., \& Ritz, A. (2003). Sensorimotor recovery in children after traumatic brain injury: Analyses of gait, gross motor, and fine motor skills. Developmental medicine and child neurology, 45(12), 821-828.

Maillard-Wermelinger, A., Yeates, K. O., Gerry Taylor, H., Rusin, J., Bangert, B., Dietrich, A.,... \& Wright, M. (2009). Mild traumatic brain injury and executive functions in school-aged children. Developmental neurorehabilitation, 12(5), 330-341.

Maxwell, W. L. (2012). Traumatic brain injury in the neonate, child and adolescent human: An overview of pathology. International journal of developmental neuroscience, 30(3), 167-183.

McKinlay, A., Grace, R. C., Horwood, L. J., Fergusson, D. M., Ridder, E. M., \& MacFarlane, M. R. (2008). Prevalence of traumatic brain injury among children, adolescents and young adults: Prospective evidence from a birth cohort. Brain injury, 22(2), 175-181.

Nadebaum, C., Anderson, V., \& Catroppa, C. (2007). Executive function outcomes following traumatic brain injury in young children: A five year follow-up. Developmental neuropsychology, 32(2), 703-728.

Pomerleau, G., Hurteau, A. M., Parent, L., Doucet, K., CorbinBerrigan, L. A., \& Gagnon, I. (2012). Developmental trajectories of infants and toddlers with good initial presentation following moderate or severe traumatic brain injury: A pilot clinical assessment project. Journal of pediatric rehabilitation medicine, 5(2), 89-97.

Puvanachandra, P., \& Hyder, A. A. (2008). Traumatic brain injury in Latin America and the Caribbean: A call for research. Salud publica de Mexico, 50(S1), 3-5.

Reitan, R.M. (1992). Trail Making Test: Manualfor Administration and Scoring. Tucson, AZ: Reitan Neuropsychology Laboratory.

Rey, A. (2009). REY: Test de copia y de reproducción de memoria de figuras geométricas complejas. Madrid: TEA ediciones.

Ryan, N. P., Catroppa, C., Beare, R., Coleman, L., Ditchfield, M., Crossley, L.,... \& Anderson, V. A. (2015). Predictors of longitudinal outcome and recovery of pragmatic language and its relation to externalizing behaviour after pediatric traumatic brain injury. Brain and language, 142, 86-95.

Schmidt, M. (1996). Rey auditory verbal learning test: A handbook (p. 1996). Los Angeles, CA: Western Psychological Services.

Thompson, N. M., Francis, D. J., Stuebing, K. K., Fletcher, J. M., Ewing-Cobbs, L., Miner, M. E.,... \& Eisenberg, H. M. (1994). Motor, visual-spatial, and somatosensory skills after closed head injury in children and adolescents: A study of change. Neuropsychology, 8(3), 333.

Treble-Barna, A., Zang, H., Zhang, N., Taylor, H. G., Yeates, K. O., $\&$ Wade, S. (2017). Long-term neuropsychological profiles and their role as mediators of adaptive functioning after traumatic brain injury in early childhood. Journal of neurotrauma, 34(2), 353-362.

Van Beek, L., Vanderauwera, J., Ghesquière, P., Lagae, L., \& De Smedt, B. (2015). Longitudinal changes in mathematical abilities and white matter following paediatric mild traumatic brain injury. Brain injury, 29(13-14), 1701-1710.

Wade, S. L., Taylor, H. G., Drotar, D., Stancin, T., \& Yeates, K. O. (1996). Childhood traumatic brain injury: Initial impact on the family. Journal of Learning disabilities, 29(6), 652-661.

Wechsler, D., \& Corral, S. (2007). WISC-IV: Escala de Inteligencia de Wechsler para niños-IV. Madrid: TEA. 